\title{
Factors influencing tourist's satisfaction, loyalty and word of mouth in selection of local foods in Pakistan
}

\author{
Muhammad Ali \\ Department of Business Administration, \\ IQRA University Karachi, Karachi, Pakistan \\ Chin-Hong Puah \\ Universiti Malaysia Sarawak, Kota Samarahan, Malaysia \\ Norazirah Ayob \\ Faculty of Economics and Business, \\ Universiti Malaysia Sarawak, Kota Samarahan, Malaysia, and \\ Syed Ali Raza \\ Iqra University, Karachi, Pakistan
}

Local foods in Pakistan
Received 6 November 2018 Revised 8 July 2019 Accepted 24 July 2019

\begin{abstract}
Purpose - Local foods from the perspective of tourism play a significant role to attract tourists. Surprisingly, empirical evidence on food tourism is quite scarce. The purpose of this paper is to develop and investigate a conceptual framework on tourist satisfaction, loyalty and word of mouth (WOM) to select local foods in Pakistan.

Design/methodology/approach - The study uses a quantitative approach while convenience (non-probability) sampling is used to collect a sample of 286 final responses using a survey-based questionnaire. The study employed exploratory factor analysis and confirmatory factor analysis to stabilize the factor structure. The conceptual model is then tested under the assumptions of structural equation modeling. Findings - The findings indicate that food quality, perceived environmental quality, perceived value and service quality has a significant impact on the tourist's satisfaction. However, interpersonal interaction quality shows an insignificant influence on satisfaction. Moreover, satisfaction has a significant impact on loyalty while loyalty further shows a significant effect on tourist WOM. Overall, the authors found satisfaction and loyalty are the major contributors to the hypothesized model.

Practical implications - The conceptual framework and study findings will support practitioners and researchers to understand the factors that influence a tourist's selection of local foods. Additionally, the study provides a useful policy to gain long-term economic benefits for the tourism sector in Pakistan.

Originality/value - To the authors' best knowledge, this study is the first attempt to explore WOM behavior in tourism research focusing on the critical role of satisfaction and loyalty. The authors are certain that the findings will contribute significantly to the existing body of knowledge.
\end{abstract}

Keywords Pakistan, Service quality, Loyalty, Food quality, Word of mouth, Tourism satisfaction

Paper type Research paper

\section{Introduction}

Tourism sector is considered as one of the most potential revenue generating and financially attractive sectors. Among other service industries, the tourism sector contributes significantly to the world economy (Guimaraes and Silva, 2016; Rahman et al., 2018; Sharma et al., 2017; Som and Badarneh, 2011). As a result, world economies are continuously investing in the tourism sector. According to Poon and Lock-Teng Low (2005), tourists' activities are dependent on features of the tourism industry which may include cultural events, shopping activities, local beverages and foods consumption, new accommodation projects and other entertainment activities. Yeoman and McMahon-Beatte (2016) and

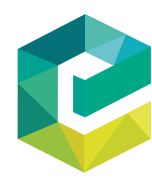

British Food Journa (C) Emerald Publishing Limited DOI 10.1108/BFJ-11-2018-0728 